International Journal of Civil, Structural,

Environmental and Infrastructure Engineering

Research and Development (IJCSEIERD)

ISSN (P): 2249-6866; ISSN (E): 2249-7978

Vol. 11, Issue 2, Dec 2021, 45-54

(C) TJPRC Pvt. Ltd.

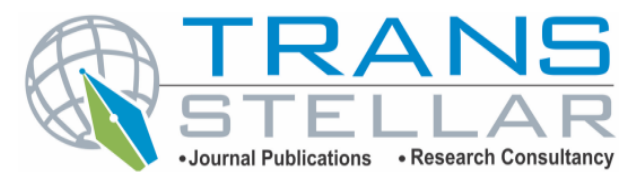

\title{
INFLUENCE OF FLY ASH ON THE MECHANICAL PROPERTIES OF GLASS FIBER REINFORCED MORTAR
}

\section{LAWI ABUBAKAR SADIQ, CHEN HAIMING \& CHEN QIAN*}

School of Civil Engineering and Architecture, Anhui University of Science and Technology,

Huainan 232001, Anhui, China

\begin{abstract}
Glass fiber reinforced cement (GRC) has many advantages such as high tensile, bending, impact resistance, and light weight, but the long-term performance degradation limits its use in a wider range. In this work, the effect of fly ash (FA) and silica fume (SF) on the mechanical properties of glass fiber reinforced cement mortar (GRCM) was investigated. Cement was replaced by FA and SF with different mass substitution rates (4\%, $8 \%, 12 \%$ and 16\%) to prepare GRCM. The mechanical properties of GRCM were tested through the compressive strength test and the flexural strength test, and the influence of FA or SF on the toughness of GRCM was evaluated by the ratio of bending-compressive strength. The research results showed that the compressive and flexural strength of GRCM decreased with the increase of FA content. FA has little effect on the ratio of bending-compressive strength of GRCM in the early stage. The ratio of bending-compressive strength of GRCM at 28d increased with the increase of FA content. When the FA content is greater than $8 \%$, the ratio of bending-compressive strength is greater than that of the control group, indicating that FA can improve the toughness of GRCM in the later stage. With the increase of the amount of SF, the compressive and flexural strength of GRCM both increased at first and then decreased. The optimum compressive strength and tensile strength was obtained at SF replacement percentage of $8 \%$ of cement. The incorporation of an appropriate amount of SF has little effect on the toughness of the mortar. Addition of FA and SF can improve the durability of GRCM.

KEYWORDS: Fly ash; silica fume; glass fiber; mechanical properties; pozzolastic reaction; the ratio of bending-compressive strength
\end{abstract}

Received: Aug 08, 2021; Accepted: Aug 28, 2021; Published: Sep 07, 2021; Paper Id.: IJCSEIERDDEC20215

\section{INTRODUCTION}

Cement concrete has the advantages of easy forming, low energy consumption, good durability, and low price, which is the largest and most widely used building material in the world[1,2]. However, traditional cement concrete has low tensile and flexural strength, low ultimate strain, poor impact resistance, easy cracking, and poor durability such as freeze-thaw resistance, shrinkage resistance, and abrasion resistance, which can cause sudden uncontrollable destruction damage to buildings, resulting in huge economic losses. Therefore, the application of cement concrete as structural load-bearing materials has been greatly restricted. Fiber reinforced cement concrete composite materials can strengthen and toughen cement concrete, improve their crack resistance and durability, and provide an effective way to obtain high performance cement concrete[3-5].

G1ass fiber reinforced cement (GRC) has the advantages of low density, high strength, good freeze-thaw resistance, excellent impermeability, high fire resistance, and strong plasticity, which is widely used in construction, civil engineering, environmental art and disaster relief and other fields[6-9]. However, with the development of age, glass fibers in concrete will continue to be corroded and become invalid in an alkaline environment. At present, the 
technical approach adopted in the production of GRC in China is using alkali-resistant glass fiber reinforced low-alkalinity sulphoaluminate cement. This method has the advantages of high early strength and good durability, but the cost of low-alkalinity sulphoaluminate cement Higher (about $650 \mathrm{CNY} /$ ton) is higher than that of ordinary Portland cement (300 CNY/ton), and fewer manufacturers of low-alkalinity sulphoaluminate cement often result in the huge transportation cost. The technology of using fly ash (FA), silica fume (SF), metakaolin and other active admixtures to modify ordinary Portland cement, and using alkali-resistant glass fiber as the reinforcing material to produce GRC has been fully valued and developed at home and abroad. This technology has the advantages of wide material sources, low cost, high durability, environmental protection and energy saving.

FA is an industrial by-product. It is estimated that FA emissions are about 900 million tons in China in 2020 [10], so how to recycle such a huge amount of FA is a particularly important problem to be solved. Tangchirapat et al. [11] studied the effect of high-fine FA on the performance of recycled aggregate concrete, and the results showed that high-fine FA, partially replacing cement, improved the properties of recycled aggregate concrete. SF is a by-product of smelting silicon products and has the characteristics of light weight and small particle size. Sadrmomtazi et al. [12] investigated the influence of SF on the mechanical strength and microstructure of basalt fiber reinforced cement-based composites (BFRCC). The results showed that $\mathrm{SF}$ addition had positive effects on the fiber-matrix transition zone structure while increasing mechanical strength and specific electrical resistivity by up to 20 times due to the pozzolanic effect of SF and the reduction of cement dosage. SF can improve the physical and mechanical properties of mortar or concrete, which can be attributed to the pozzolanic reaction between $\mathrm{SF}$ and $\mathrm{Ca}(\mathrm{OH})_{2}$ to produce more gelled products and refine the pore structure.

The mechanism of FA and SF strengthening and improving the durability of GRC is as follows. FA, SF and other active admixtures replace part of ordinary Portland cement, the amount of cement is reduced, and the total amount of $\mathrm{Ca}(\mathrm{OH})_{2}$ generated is reduced. Active admixtures such as FA and SF will react with the $\mathrm{Ca}(\mathrm{OH})_{2}$ produced by cement hydration, which further consumes part of $\mathrm{Ca}(\mathrm{OH})_{2}$, resulting in a decrease in alkalinity in the system pore solution. In addition, the incorporation of active mineral admixtures will form a large amount of low alkalinity hydrated calcium silicate gel in the GRC hydrate products, which can absorb and fix a large amount of $\mathrm{Na}^{+}$and $\mathrm{K}^{+}$ions, so that the effective alkali content in concrete pore solution is greatly reduced. When the alkalinity in the pore solution is too low to reach the activation energy required for the $\mathrm{OH}^{-}$to react with the glass fiber components, the erosion of the glass fiber is reduced or even eliminated. At the same time, FA and SF can also improve the interface between the matrix and the glass fiber, and reduce the physical and stress corrosion of the glass fiber by $\mathrm{Ca}(\mathrm{OH})_{2}$.

In this study, FA and SF were added into alkali-resistant glass fiber reinforced cement mortar (GRCM) to further improve its mechanical properties and durability. The research results showed that FA reduced the compressive and tensile strength of GRCM to a certain extent, but FA can improve the toughness of the mortar in the later stage. With the increase of the amount of SF, the compressive and flexural strength of GRCM increased at first and then decreased. The incorporation of a proper amount of SF has little effect on the toughness of GRCM. The incorporation of FA and SF can improve the durability of incorporation. This result has important guiding significance for realizing the recycling of industrial wastes of mineral admixtures with pozzolanic activity such as FA and SF, improving the mechanical properties of GRCM and improving its durability.

\section{MATERIAL AND METHODS}

\subsection{Raw Materials}

The cement used in this work were P.O 32.5 ordinary Portland cement produced by Huainan Shunyue Cement Co., Ltd.(China), with a density of $3,060 \mathrm{~kg} / \mathrm{m}^{3}$. The FA used was a class F FA produced by a thermal power plant in Huainan, with a density of $2700 \mathrm{~kg} / \mathrm{m}^{3}$ and a specific surface area of $1535 \mathrm{~m}^{2} / \mathrm{g}$, as shown in Figure 1 . The SF used was purchased from 
Xi'an Linyuan Microsilica Powder Co., Ltd. (China), with an average particle size of 0.1 0.3 $\mu$ m and a specific surface area of $27000 \mathrm{~m}^{2} / \mathrm{g}$, as shown in Figure 2. The fiber was ordinary glass fiber, as shown in Figure 3. The sand was Huaihe River sand. The chemical composition of each raw material is shown in Table 1.

Table 1: The Main Chemical Composition of Raw Materials

\begin{tabular}{|c|c|c|c|c|c|c|}
\hline \multirow{2}{*}{ Raw materials } & \multicolumn{5}{|c|}{ Chemical composition /wt\%(XRF) } \\
\cline { 2 - 7 } & $\mathbf{C a O}$ & $\mathbf{S i O}_{\mathbf{2}}$ & $\mathbf{A l}_{\mathbf{2}} \mathbf{O}_{\mathbf{3}}$ & $\mathbf{S O}_{\mathbf{3}}$ & $\mathbf{M g O}$ & $\mathbf{F e}_{2} \mathbf{O}_{3}$ \\
\hline FA & 3.50 & 57.00 & 26.10 & 0.70 & 0.70 & 4.20 \\
\hline P.O 32.5 cement & 41.96 & 22.06 & 11.49 & - & 0.68 & 3.06 \\
\hline SF & 0.40 & 95.70 & 1.10 & - & 0.80 & 1.00 \\
\hline
\end{tabular}

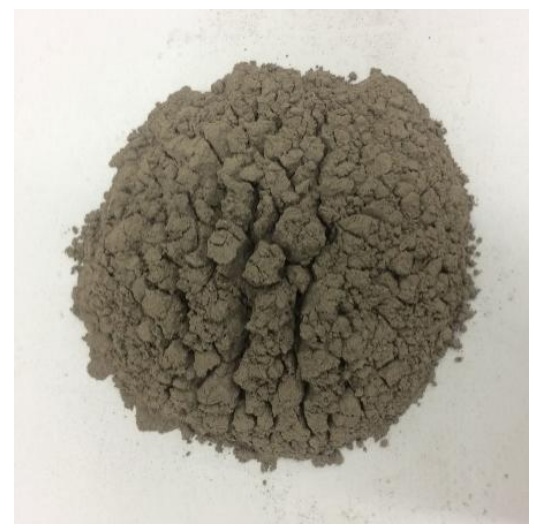

Figure 1: Picture of FA

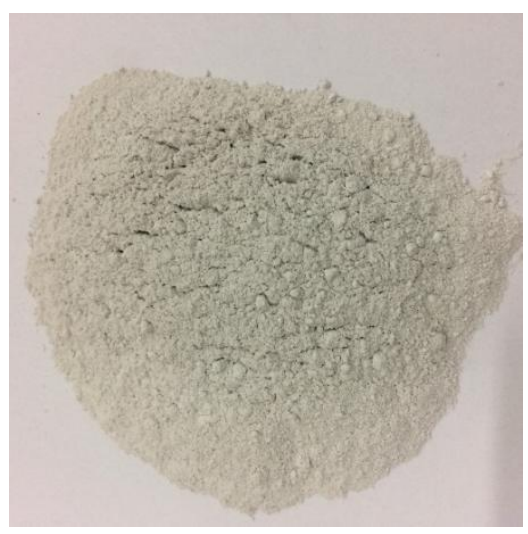

Figure 2: Picture of SF

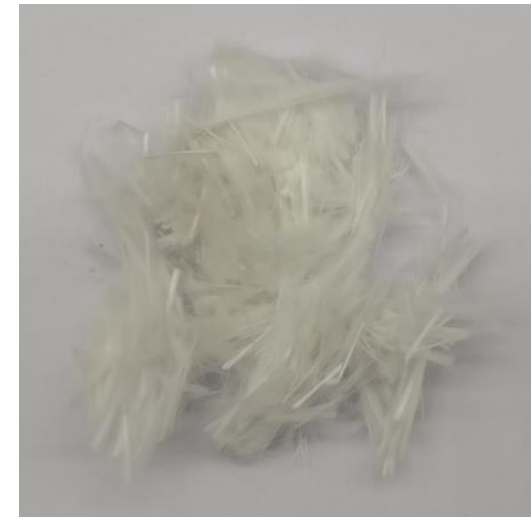

Figure 3: Picture of glass fiber

\subsection{Mix Proportions}

This experiment was carried out to investigate the influence of FA and SF on the mechanical properties and toughness of GRCM. The glass fiber content was $2 \%$ by volume, the water-binder ratio of GRCM was 0.38 , and the binder-sand ratio was 1:1.2. FA and SF replaced 4\%, $8 \%, 12 \%$ and $16 \%$ of cement by weight respectively. The mix proportions of GRCM are shown in Table 2. Con represents the control group, FA represents fly ash, SF represents silica fume, and the numbers after FA and SF represent the replacement percentage.

\subsection{Flexural and Compressive Strength Test}

The compressive and flexural strength of GRCM specimens were determined according to ASTM C349-18[13] and ASTM C348-21[14], by molding 81 prism specimens, $40 \mathrm{~mm} \times 40 \mathrm{~mm} \times 160 \mathrm{~mm}$. GRCM specimens were removed from the molds after curing for 24 hours in a standard curing room at a relative humidity more than $95 \%$ and a temperature of $(23 \pm 1)^{\circ} \mathrm{C}$. Then the specimens were immersed in saturated calcium hydroxide solution for $3 \mathrm{~d}$, 7d, and 28d. First, GRCM specimen s were used for flexural strength testing, and then both portions from each prism broken in flexure were used for compression testing. and the average value was taken. The mean values of compressive and flexural strength of GRCM specimens were reported. 
Table 2: Mix Proportions of GRCM $\left(\mathrm{kg} / \mathrm{m}^{3}\right)$

\begin{tabular}{|c|c|c|c|c|c|c|}
\hline Sample & P.O32.5 cement & Sand & Water & Glass fiber & FA & SF \\
\hline Con & 755.0 & 906.0 & 286.9 & 48.7 & 0.0 & 0.0 \\
\hline FA4 & 724.8 & 906.0 & 286.9 & 48.7 & 30.2 & 0.0 \\
\hline FA8 & 694.6 & 906.0 & 286.9 & 48.7 & 60.4 & 0.0 \\
\hline FA12 & 664.4 & 906.0 & 286.9 & 48.7 & 90.6 & 0.0 \\
\hline FA16 & 634.2 & 906.0 & 286.9 & 48.7 & 120.8 & 0.0 \\
\hline SF4 & 724.8 & 906.0 & 286.9 & 48.7 & 0.0 & 30.2 \\
\hline SF8 & 694.6 & 906.0 & 286.9 & 48.7 & 0.0 & 60.4 \\
\hline SF12 & 664.4 & 906.0 & 286.9 & 48.7 & 0.0 & 90.6 \\
\hline SF16 & 634.2 & 906.0 & 286.9 & 48.7 & 0.0 & 120.8 \\
\hline
\end{tabular}

\section{RESULTS AND DISCUSSION}

\subsection{Compressive Strength}

Figure 4 presents the compressive strength of GRCM with different FA content at $3 \mathrm{~d}$, $7 \mathrm{~d}$ and $28 \mathrm{~d}$. As the age increased, compressive strength of GRCM showed an increasing trend, and the addition of FA influenced the comprehensive strength development of GRCM at all ages. It can be seen from Figure 4 that when the amount of FA was 4\%, the compressive strength of GRCM at $3 \mathrm{~d}$ and $7 \mathrm{~d}$ were higher than that of the control group. This is because when the content of FA is low, the addition of FA will increase early hydration velocity of cement in GRCM, which can increase the early compressive strength of GRCM.

When FA content was more than 4\%, the compressive strength of GRCM at $3 \mathrm{~d}$ and $7 \mathrm{~d}$ was lower than that of the control group, and the compressive strength decreased with the increase of the amount of FA. At the age of 28 days, the compressive strength of each group of GRCM decreased with the increase of FA content. This is because FA has active or negative effects on the compressive strength development of GRCM. The positive effect of FA includes: (1) The average particle size of FA is less than $0.1 \mu \mathrm{m}$, which is about $1 / 50 \sim 1 / 10$ of the particle size of cement. FA can play a micro-filling effect in GRCM, reducing the porosity of GRCM and increasing its compactness. The micro-aggregate effect of FA makes the FA particles evenly distributed in the cement particles, preventing the cement particles from cohesive, which is conducive to the hydration of cement, resulting in the increase of dense degree and the compressive strength of GRCM. (2) The glassy $\mathrm{SiO}_{2}$ and $\mathrm{Al}_{2} \mathrm{O}_{3}$ contained in $\mathrm{FA}$ react with $\mathrm{Ca}(\mathrm{OH})_{2}$ generated by cement hydration to form a large amount of CSH. As the pozzolanic reaction continues, the content of $\mathrm{Ca}(\mathrm{OH})_{2}$ gradually decreases, and the $\mathrm{CSH}$ gel products increases, which improves the transition zone between the glass fiber and the cement paste, also resulting in increase of the compressive strength of GRCM. However, FA has a weak pozzolanic activity, pozzolanic reaction only takes place under certain alkalinity conditions at room temperature, that is, it lags behind the hydration of cement. Therefore, the early strength of GRCM is mainly determined by cement hydration. Addition of FA in GRCM results in decrease of the amount of cement. When the amount of FA is large, the $\mathrm{Ca}(\mathrm{OH})_{2}$ produced by cement hydration is not enough to stimulate the activity of FA, and the increase of GRCM strength caused by the micro-aggregate effect and the pozzolanic effect of FA cannot compensate for the decrease of GRCM strength caused by reducing the amount of cement, resulting in decrease of the compressive strength of GRCM. In addition, because the specific surface area of FA is much larger than that of cement, with the increase in FA content, the water demand and the drying shrinkage of GRCM increases, so the compressive strength of GRCM is reduced. 


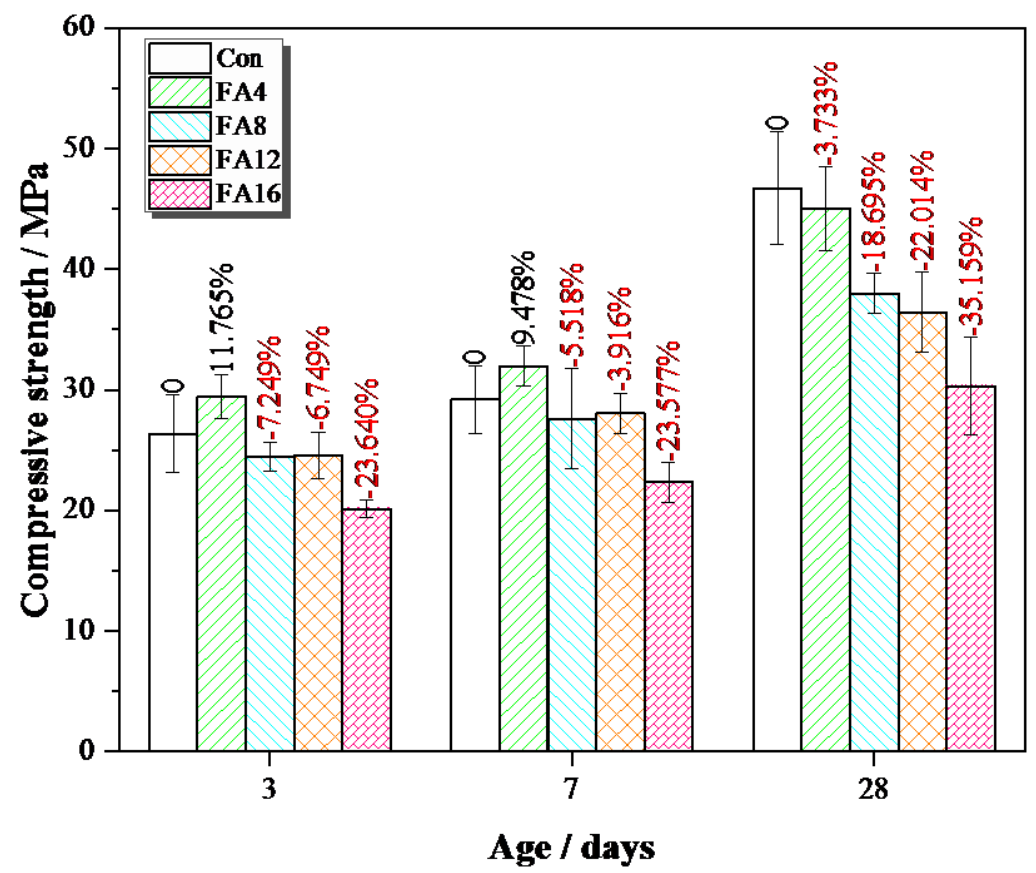

Figure 4: Compressive Strength of GRCM with FA

igure 5 shows the compressive strength of GRCM with different SF content at 3d, 7d and 28d. With the increase of age, the compressive strength of GRCM showed an increasing trend, and incorporation of SF has a significant effect on the comprehensive strength development of GRCM at all ages. The compressive strength of GRCM at first increased and then decreased with the increase of SF content at all ages. The optimum compressive strength of GRCM was obtained when the SF content was $8 \%$. This shows that, unlike FA, the incorporation of SF can not only increase the early strength of GRCM, but also increase the late strength of GRCM. Possible reasons are as follows. On the one hand, the particle size of SF is very small, about 1/100 1/50 of the particle size of cement. SF particle can fill the voids of cement particles and the pores of cement paste, increasing dense degree of GRCM, thereby improving the compressive strength. On the other hand, the main chemical component of $\mathrm{SF}$ is amorphous $\mathrm{SiO}_{2}$ with strong pozzolanic activity. Secondary hydration reaction between $\mathrm{SF}$ and $\mathrm{Ca}(\mathrm{OH})_{2}$ generated by cement hydration takes place to produce $\mathrm{CSH}$ gel, which can not only reduce the content of $\mathrm{Ca}(\mathrm{OH})_{2}$ in the cement paste, but also increase the amount of CSH gel, improving the microstructure of the pores, resulting in increase of compressive strength of GRCM. However, due to the very small particle size of SF, its specific surface area is much larger than that of cement. As the amount of SF increases, the water demand of GRCM and the dry shrinkage increases, resulting in decrease of compressive strength of GRCM. In addition, SF partial replacement of cement reduces the amount of cement in GRCM, so the amount of the cementitious materials produced by cement hydration, which causes a decrease in compressive strength of GRCM. 


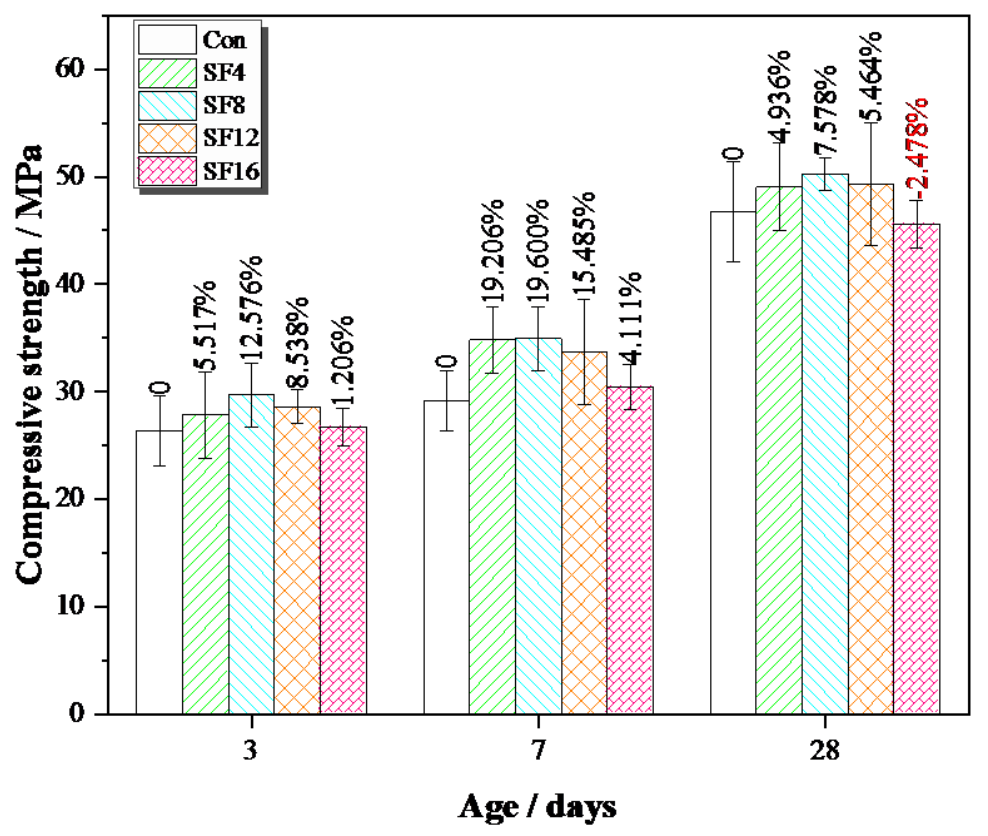

Figure 5: Compressive Strength of GRCM with SF

\subsection{Flexural Strength}

The flexural strengths of GRCM with different FA content cured for $3 d, 7 d$ and $28 d$ are shown in Figure 6 . It can be seen from Figure 6 that as the age increased, the flexural strength of GRCM showed an increasing trend, which showed the amount of FA had an effect on the flexural strength of t GRCM at all ages. At the age of $3 \mathrm{~d}$ and $7 \mathrm{~d}$, similar to the development trend of compressive strength, the flexural strength of GRCM with 4\% FA was slightly greater than that of the control group, and with the increase of the FA content, the flexural strength decreased significantly. Incorporating a small amount of FA into GRCM enhanced its flexural strength to a certain extent, but as the amount of FA increased, the flexural strength decreased significantly. This is because when the content of FA is low, FA will accelerate the early hydration of cement, thereby improving the early flexural strength of GRCM. However, the activity of FA is much smaller than that of cement. When the amount of FA addition is large, the $\mathrm{Ca}(\mathrm{OH})_{2}$ produced by cement hydration is not enough to stimulate its activity. The increase of flexural strength of GRCM caused by the micro-aggregate effect and the pozzolanic effect of FA cannot compensate for the decrease in strength caused by the decrease of cement consumption. In addition, due to the small particles of FA, the specific surface area is larger than that of cement. As the amount of FA increases, the water demand of GRCM increases and the drying shrinkage increases, so the flexural strength is reduced. At the age of 28 days, due to the combined effect of the micro-aggregate effect of FA, the pozzolanic effect, and the reduction in the amount of cement, the flexural strength of GRCM mixed with FA was lower than that of the control group. 


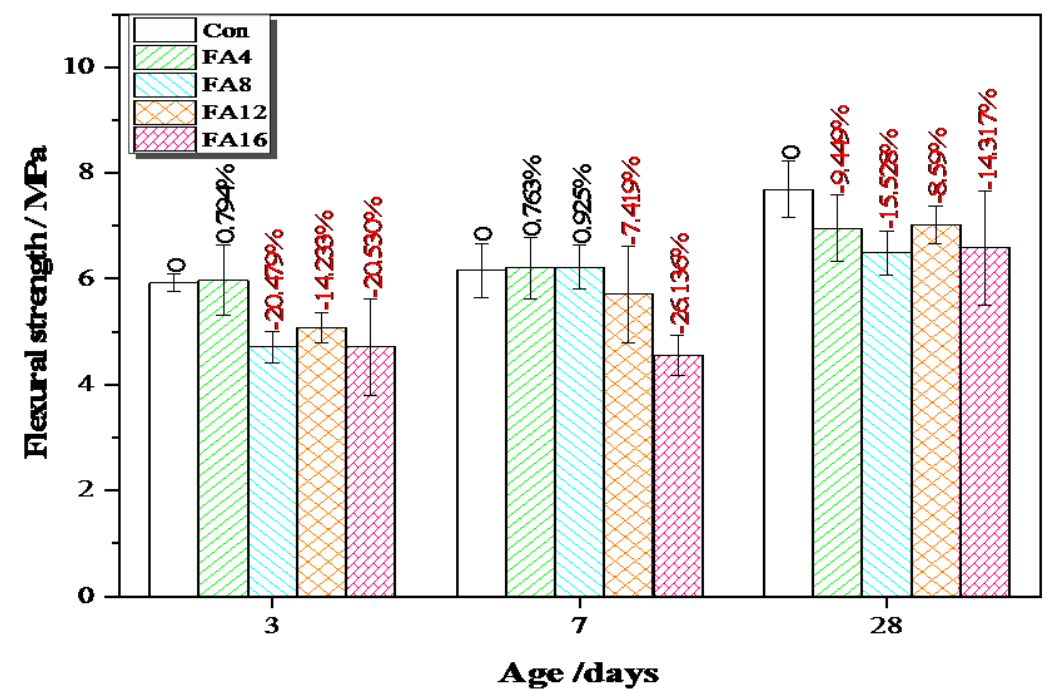

Figure 6: Flexural Strength of GRCM with FA

The influence of adding SF on the flexural strength of GRCM is shown in Figure 7. Similar to the law of compressive strength, with the increase of age, the flexural strength of GRCM continued to increase, and SF had an effect on the flexural strength of GRCM at all ages. It can be seen from Figure 7 that the flexural strength of GRCM cured for $3 \mathrm{~d}$ decreased with the increase of SF content; at 7d and 28d age, the flexural strength of GRCM at first increased and then decreased with the increase of SF content. GRCM reached its maximum flexural strength when SF content was $8 \%$. It means that the incorporation of an appropriate amount of SF can increase the flexural strength of GRCM. The reason is that $\mathrm{SF}$ has a higher pozzolanic activity and reacts with $\mathrm{Ca}(\mathrm{OH})_{2}$ produced by cement hydration to produce more expansive products that fill the pores between mortar particles and glass fibers. However, excessive SF will have a dilution effect on the cement mortar. The substitution of SF for cement is equivalent to a reduction in the amount of cement, and the amount of cementing materials produced by cement hydration is reduced, resulting in a decrease in the flexural strength of GRCM. In addition, the particle size of SF is very small, and its specific surface area is much larger than that of cement. As the amount of SF increases, the water demand of the mortar increases, the shrinkage increases, and the cracks increase, which will also cause the flexural strength to decrease.

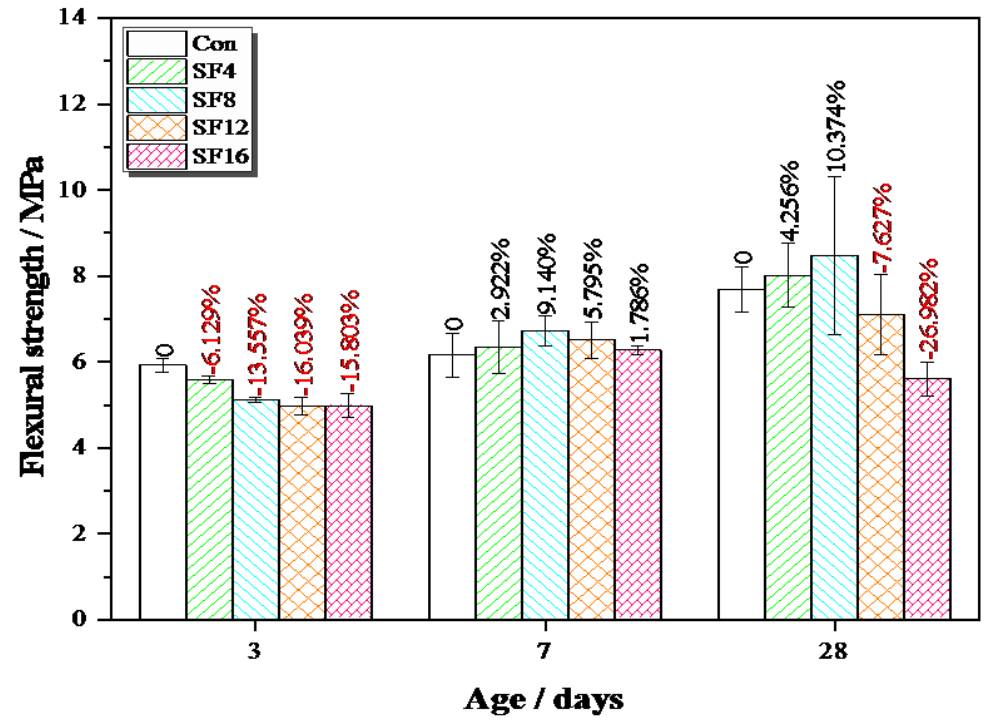

Figure 7: Flexural strength of GRCM with SF 


\subsection{Ratio of Bending-Compressive Strength}

Ratio of bending-compressive strength is the ratio of flexural strength to compressive strength, which can reflect the toughness of concrete or mortar. The larger the ratio, the better the toughness of concrete or mortar. Figure 8 shows ratio of bending-compressive strength of GRCM with different FA content cured for $3 \mathrm{~d}, 7 \mathrm{~d}$ and $28 \mathrm{~d}$. It can be seen from figure 8 that the incorporation of FA had a significant effect on ratio of bending-compressive strength of GRCM. In the early stage ( $3 \mathrm{~d}$ and 7d), ratio of bending-compressive strength of each group did not change much compared with the control group. This is because the activity of FA is less than that of cement, and the $\mathrm{Ca}(\mathrm{OH})_{2}$ produced by early cement hydration is not enough to stimulate its activity. The replacement of cement by FA is equivalent to a reduction in the amount of cement. The compressive and flexural strengths are reduced as result of the reduction in the amount of cementing material produced by cement hydration. With the increase of age, it may be that the fiber was corroded in the alkaline environment, and ratio of bending-compressive strength of the control group decreased. However, at the age of $28 \mathrm{~d}$, ratio of bending-compressive strength of GRCM increased with the increase of FA content and the ratio of GRCM with FA content greater than 8\% was higher than that of the control group, indicating that FA can increase the ratio of bending-compressive strength of GRCM at the later stage, which is beneficial to improve the toughness of GRCM at the later stage. This is because the pozzolanic activity of FA was activated and secondary hydration reaction between FA and hydration products of cement occurred, the amount of $\mathrm{Ca}(\mathrm{OH})_{2}$ in GRCM was reduced, the alkalinity of GRCM became weaker, and the corrosiveness to the glass fiber was greatly reduced. Therefore, incorporation of FA not only improves the toughness of GRCM in the late stage but also improves its durability and expand the application range of GRCM.

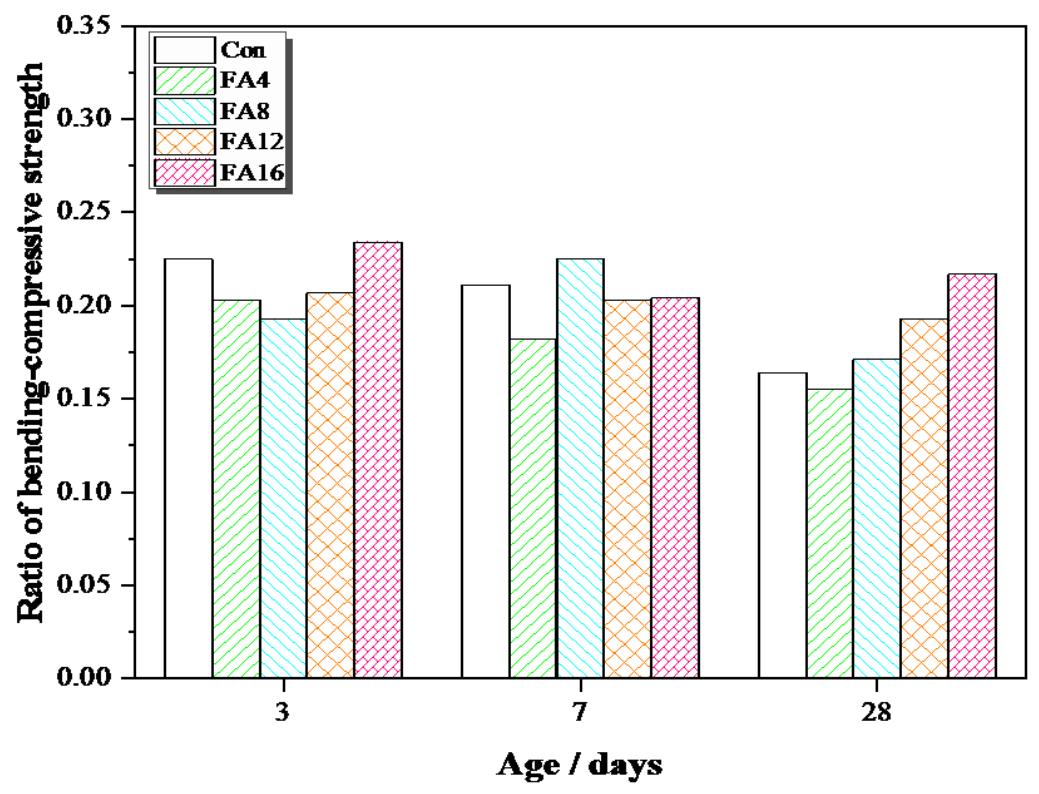

Figure 8 Ratio of bending-Compressive Strength of GRCM with FA

Figure 9 presents ratio of bending-compressive strength of GRCM with different SF content. at 3d, 7d and 28d. At the age of $3 \mathrm{~d}$ and $7 \mathrm{~d}$, the ratio of bending-compressive strength of GRCM with SF was lower than that of the control group, but the effect was small. This is because the compressive strength and flexural strength of GRCM both increased at first and then decreased with the increase of SF content. At 28 days, the hydration reaction was relatively sufficient, the corrosion of the fibers began to appear, and ratio of bending-compressive strength of the control group was greatly reduced. However, GRCM with SF increased at first and then decreased with increase of the amount of SF. Among them, ratio of bending-compressive strength of GRCM with $8 \%$ SF content was slightly bigger than the control group. When the content of 
SF was more than $8 \%$, ratio of bending-compressive strength of GRCM began to decrease. It shows that the incorporation of a proper amount of SF does not have much effect on the toughness of GRCM, but it can improve the durability of GRCM.

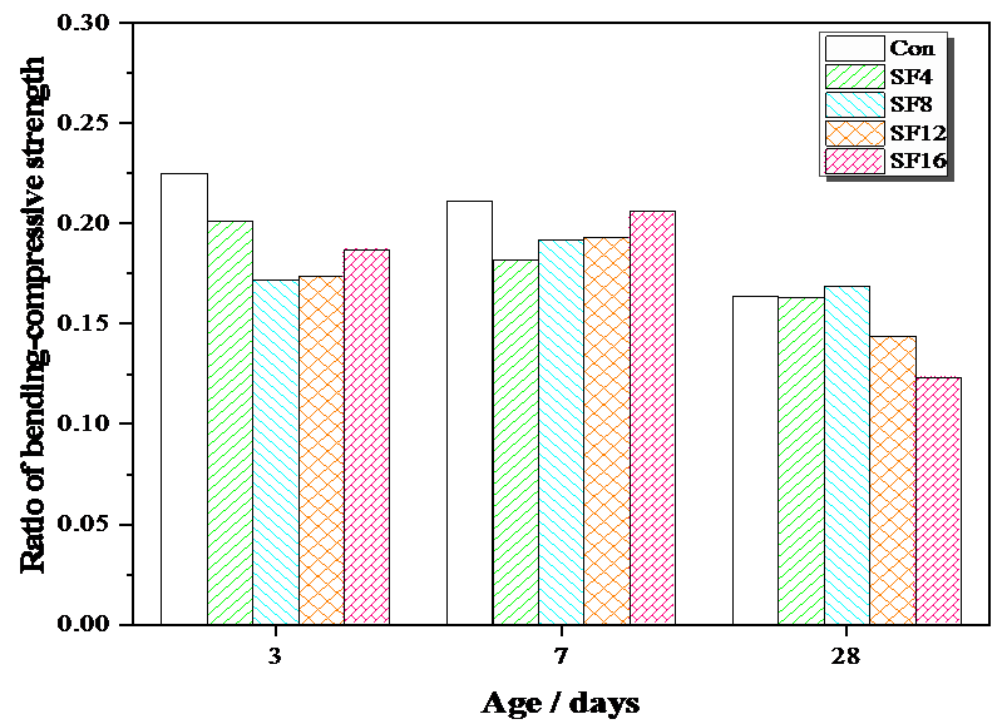

Figure 9: The ratio of bending-Compressive Strength of GRCM with SF

\section{CONCLUSIONS}

This paper investigated the effect of FA and SF content on mechanical properties of GRCM. Conclusions are drawn based on the experimental results.

- The compressive and flexural strength of GRCM decreased with the increase of FA content. FA has little effect on ratio of bending-compressive strength of GRCM in the early stage, and the ratio increased with the increase of FA content in the later stage. FA can improve the toughness of GRCM in the later stage.

- The compressive and flexural strength of GRCM both increased at first and then decreased with the increase of SF. $8 \%$ was the optimal amount of SF. The incorporation of an appropriate amount of SF has little effect on the toughness of GRCM.

- Adding FA and SF in GRCM is conducive to recycling of industrial wastes and the durability improvement of GRCM.

\section{REFERENCES}

1. Fa-Tang LI, Luo Q Z, Wang D S, et al (2003). Advantages and Present Research of Belite Cement[J]. Heb Journal of Industrial Science \& Technology.

2. Gemert D V (2007). Cement concrete and concrete-polymer composites: Two merging worlds[J]. xiith interantional congress on polymers in concrete.

3. Yurdakul, Arife, Dolekcekic, et al (2018). The usage of newly developed glass fibre in cement structure and their characterization [J]. Construction and building materials. 
4. Juhui Cao, Hongtao Wang (2004). Progress of research on durability of glass fiber reinforced cement[J]. Architecture technology, (04):266-269(in Chinese).

5. Wangtian Zhang, Yunsheng Zhang, ZhitaoWu, et al (2019). Optimization Design and Properties of Glass Fiber Reinforced Cementitious Composites[J]. Materials reports, (33):2331-2336(in Chinese).

6. Hongtao Wang, Juhui Cao (2007). Preparation technology of GRC of low cost, high durability and environment protection[J]. Architecture technology, (02):148-151(in Chinese).

7. Yang Cao, Yin Tian, Na Zhou,et al (2007). Study on improving durability of GRC by pretreatment of glass fiber[J]. New wall materials (in Chinese).

8. Thwe M M, Liao K (2002). Effects of environmental aging on the mechanical properties of bamboo-glass fiber reinforced polymer matrix hybrid composites[J]. Composites Part A Applied Science \& Manufacturing, 33(1):43-52.

9. Criado M, I García-Díaz, Bastidas J M, et al (2014). Effect of recycled glass fiber on the corrosion behavior of reinforced mortar[J]. Construction and Building Materials, 64(1):261-269.

10. Yuanfeng Wu, Guiyun Yi, Quanrun Liu,et al (2013). Present situation of comprehensive utilization of fly ash[J]. Clean coal technology, (06): 107-111(in Chinese).

11. Tangchirapat W, Buranasing R, Jaturapitakkul C (2009). Use of high fineness of fly ash to improve properties of recycled aggregate concrete[J]. Journal of Materials in Civil Engineering, 22(6): 565-571.

12. Sadrmomtazi A, Tahmouresi B, Saradar A (2018). Effects of silica fume on mechanical strength and microstructure of basalt fiber reinforced cementitious composites (BFRCC) [J]. Construction and Building Materials, 162: 321-333.

13. ASTM C349-18, Standard Test Method for Compressive Strength of Hydraulic-Cement Mortars (Using Portions of Prisms Broken in Flexure), ASTM International, West Conshohocken, PA, 2018, www.astm.org.

14. ASTM C348-21, Standard Test Method for Flexural Strength of Hydraulic-Cement Mortars, ASTM International, West Conshohocken, PA, 2021, www.astm.org.

15. Kiran, T. Sai. "Comparision Of Split Tensile Strength And Flexural Of Glass Fiber Reinforced Concrete With Conventional Concrete." International Journal of Civil, Structural, Environmental and Infrastructure Engineering Research and Development (IJCSEIERD) Vol 6 (2016): 35-42.

16. Kinoshita, H. I. R. O. Y. U. K. I., et al. "Environmental Harmony-Type Pavement Blocks Made from Clay and Waste GFRP." International Journal of Civil, Structural, Environmental and Infrastructure Engineering Research and Development 6.1 (2016): 51-60.

17. Kumar, Duppala Ajay Kumar1\& Ch Bharath. "Processing And Mechanical Behaviour Of Human Hair Fiber Reinforced Polymer Composites." International Journal of Mechanical and Production Engineering Research and Development (IJMPERD) 8 (2018): 107-116.

18. Nibudey, R. N., et al. "Strength and fracture properties of post consumed waste plastic fiber reinforced concrete." International Journal of Civil, Structural, Environmental and Infrastructure Engineering Research and Development (IJCSEIERD) 3.2 (2013): 9-16.

19. Ravikumar, C. Selin, and T. S. Thandavamoorthy. "Application of FRP for strenghtening and retrofitting of civil engineering structures." Int. J. Civ. Struct. Env. Infrastr. Eng. Res. Dev 4 (2014): 49-60. 